\title{
Randomized controlled trial of Letrozole versus Clomiphene citrate for induction of ovulation in polycystic ovarian syndrome (PCOS): A Malaysian experience
}

\author{
Nik Hazlina Nik Hussain ${ }^{1 *}$, Munawwirah Ismail ${ }^{1}$, Murizah Mohd. Zain ${ }^{2}$, Pu Chan Yeu ${ }^{1}$, \\ Roszaman Ramli ${ }^{3}$, Wan Mohd Zahiruddin Wan Mohammad ${ }^{1}$ \\ ${ }^{1}$ School of Medical Sciences, Universiti Sains Malaysia and Hospital Universiti Sains Malaysia, Kelantan, Malaysia \\ ${ }^{2}$ Department of Obstetrics and Gynaecology, Hospital Sultanah Bahiyah, Alor Setar, Malaysia \\ ${ }^{3}$ Department of Obstetrics and Gynaecology, International Islamic University, Kuantan, Malaysia \\ Email: hazlina2006@yahoo.com
}

Received 4 May 2013; revised 6 June 2013; accepted 13 June 2013

Copyright (C) 2013 Nik Hazlina Nik Hussain et al. This is an open access article distributed under the Creative Commons Attribution License, which permits unrestricted use, distribution, and reproduction in any medium, provided the original work is properly cited.

\begin{abstract}
Background: The purpose of this study was to compare the effectiveness of Letrozole versus Clomiphene citrate for ovulation induction in polycystic ovarian syndrome (PCOS) with infertility. Methods: This was a prospective randomized trial involving 150 women with PCOS attending the Infertility Clinic at three hospitals in Malaysia. During the initial visit, anthropometric measurements and baseline investigations were performed. Patients were randomized to $5.0 \mathrm{mg}$ Letrozole daily (75 patients) or $100 \mathrm{mg}$ Clomiphene citrate daily (75 patients) from the fifth until the ninth day of menstruation. Serial transvaginal scans were performed to see the dominant follicles, endometrial thickness and number of follicles. Transvaginal scans were performed serially to look for evidence of ovulation. Results: The subjects were homogenously distributed. The difference between Letrozole and Clomiphene citrate for ovulation rate was $59(78.7 \%)$ versus 40 (53.3\%). Patients taking Letrozole exhibited a mean endometrial thickness (ET) at mid cycle of menses (Day 11-D14) of $9.2 \mathrm{~mm}$ (SD \pm 2.3 ) versus $8.4 \mathrm{~mm}(\mathrm{SD} \pm 2.2)$ for patients taking Clomiphene citrate, and these differences were statistically significant $(p<0.001)$. In terms of pregnancy rate, Letrozole facilitated pregnancy induction in 19 patients $(25.3 \%)$ versus 12 patients (16.0\%) for Clomiphene citrate; however, this was not statistically significant $(p=0.22)$. More dominant follicles exhibiting a monofollicular morphology were observed in patients treated with Letrozole compared
\end{abstract}

${ }^{*}$ Corresponding author. to patients treated with Clomiphene citrate, with a monofollicular dominant follicle observed in 33 (46.5\%) versus $20(26.7 \%)$ patients, respectively. Conclusion: Letrozole provided a more efficient stimulation compared to Clomiphene citrate in terms of ovulation induction, thickening of the endometrial lining and achievement of a successful pregnancy. Clinical Trials. gov Identifier: NCT015-77017.

Keywords: Polycystic Ovarian Syndrome; Ovulation Induction; Clomiphene Citrate; Letrozole

\section{INTRODUCTION}

Polycystic ovarian syndrome (PCOS) is the most common endocrinopathy, affecting $6 \%$ of women within of reproductive age [1]. The overall prevalence of PCOS among reproductive-age women in the United States (US) was $4 \%$ [2].

Clomiphene citrate has been the first-line and standard drug treatment for PCOS for the last 40 years. Early studies proved that up to $80 \%$ of anovulatory patients responded well to Clomiphene citrate as assessed by achievement of ovulation, with about half of those who were ovulatory achieving pregnancy. However, approximately $20 \%$ of patients required a high dose of Clomiphene citrate ( $200 \mathrm{mg}$ daily taken for 5 days early in the cycle), which may be a result of anti-estrogenic activities on the endometrium and cervical mucus.

Letrozole was proposed as an alternative to clomiphene citrate as a highly selective aromatase inhibitor that prevents androgen-to-estrogen conversion. This aromatase inhibitor has a short half-life (45 hours); thus 
it is rapidly eliminated from the body. No adverse effects on estrogen target tissues or down regulation of estrogen receptor (ER) is seen with Letrozole due to this short half-life, unlike Clomiphene citrate [3].

The aim of aromatase inhibitor was to avoid the peripheral anti-estrogenic effects of Clomiphene citrate, especially thinning of the endometrial lining [4]. Hence, a prospective open-labeled randomized controlled trial was conducted to determine which regime, Clomiphene citrate or Letrozole, was the best ovulation induction agent in infertile women with PCOS.

\section{METHODS}

This study consists of 150 participants enrolled in the infertility clinics at Hospital Sultanah Bahiyah (HSB), Alor Star, Kedah; Hospital Universiti Sains Malaysia (HUSM), Kelantan and Hospital Tengku Ampuan Afzan (HTAA), Kuantan, Pahang between May 2008 and May 2009 (Figure 1).

Inclusion criteria were an age between 18 years and 40 years old, diagnosed with PCOS by the Rotterdam criteria (2003) and normal seminal fluid analysis (SFA) [5]. Patients were not illiterate and consented to participate in the study. Exclusion criteria were having medical problems such as renal disease, thyroid disorder, hyperprolactinemia, liver disease or having other causes of anovulatory infertility

Power calculations were performed to determine the sample size. Based on prior data, ovulation rate among patients treated with clomiphene citrate was approximately $60 \%$ [6]. If a $25 \%$ higher rate in ovulation among patients in the intervention (Letrozole) group is assumed to be clinically relevant, with a power of $90 \%$ and statistical significance $(\alpha)$ of 0.05 , we would need a minimum of 64 patients in each arm. Taking into account a dropout rate of $20 \%, 150$ patients were recruited. They were assigned to either the Letrozole or Clomiphene citrate group via computer block randomization and identified based on their identification card number.

\subsection{Letrozole Group}

Patients in this group were given Letrozole $5.0 \mathrm{mg}$ daily from Day 5-Day 9 of menstruation. Base line transvaginal ultrasound (TVS) on the second day of menstruation was performed, following spontaneous menses by induction with medroxyprogesterone acetate (MPA) $10 \mathrm{mg}$ daily for five days with serial TVS to document ovulation. If a dominant follicle (DF) was present (DF > $12 \mathrm{~mm}$ ), a repeat TVS was performed every 2 days. Ovulation was diagnosed when the mature DF was approximately 18 to $22 \mathrm{~mm}$ followed by evidence of rupture approximately 3 to 4 days later. If a dominant follicle (DF) was absent (DF $<12 \mathrm{~mm}$ ), a repeat TVS was performed every 3 - 4 days later. Endometrial thickness (ET) was measured at every follow-up. If there was absence of a dominant follicle (DF $<12 \mathrm{~mm}$ ) up to Day 20 , the patient was considered to be anovulatory.

\subsection{Clomiphene Citrate Group}

Patients were given Clomiphene citrate $100 \mathrm{mg}$ daily from Day 5-Day 9 of menses. Those patients who had spontaneous menstruation following induction with MPA $10 \mathrm{mg}$ daily for 5 days were reviewed on the second day (baseline TVS) of their menstruation and baseline ultrasound (TVS) was performed to measure the number, size and location of the follicles on each ovary, as well as endometrial thickness (ET). TVS was repeated on the tenth day of menstruation, where the presence, number and size of the dominant follicles (DF) were evaluated. DFs were defined as follicles measuring at least $12 \mathrm{~mm}$ on the tenth day of menstruation. Serial transvaginal scans were performed to document the evidence of ovulation. If a dominant follicle (DF) was present (DF > $12 \mathrm{~mm}$ ), a repeat TVS was performed every 2 days. Ovulation was diagnosed when the mature DF was approximately 18 to $22 \mathrm{~mm}$ followed by evidence of rupture approximately 3 to 4 days later. If the dominant follicle (DF) was absent (DF $<12 \mathrm{~mm}$ ), a repeat TVS was performed every 3 - 4 days later. The absence of a dominant follicle (DF $<12 \mathrm{~mm}$ ) by Day 20 was considered as a failed induction or anovulation.

The investigator and the subject could choose to cease the study treatment or withdraw at any time, respectively.

All patients had a urine-based pregnancy test at 3 weeks after documented ovulation and continued amenorrhea. They were followed-up with until an ultrasound could document the viability of pregnancy. Primary outcome measures were ovulation rate, single follicle formation and endometrial thickness, while secondary outcome measure was pregnancy rate. The patients were given only one cycle of treatment for the study.

\subsection{Statistical Analysis}

Data entry and statistical analyses were performed using SPSS version 18. Means and standard deviations for numerical variables and frequency and proportion for categorical variables are reported. Two-tailed independent t-test was used to compare means and proportion was compared with the Chi-Square test or Fisher's exact test. A p value of $<0.05$ was considered significant. Multiple logistic regression analysis was performed to assess the association of Letrozole and Clomiphene citrate with the ovulation rate after 
controlling for confounders.

Simple logistic regression was used in univariate analysis as a screening in the selection of variables for further analysis. All variables with a $p$ value less than 0.25 were selected for inclusion in multiple logistic regression analysis.

Multiple logistic regression was chosen as the dependent variable of the binary outcome. Level of significance was $5 \%$ and results had $95 \%$ confidence intervals. The independent variables were a mix of numerical and categorical variables. Backward and forward stepwise procedure was used for variable selection. Interactions between pairs of variables from all variables in the main effect model were checked. Findings in the final model were presented as an adjusted odds ratio $(\mathrm{OR})$, its 95\% confidence interval (CI) and corresponding $\mathrm{p}$ value.

\subsection{Approval by the Research and Ethics Committee}

The protocol was approved by the Research and Ethical Committee, School of Medical Sciences, Universiti Sains Malaysia (ref: USMKK/PPP/JEPeM [(213.3.(11)], National Institutes of Health Approval For Conducting Research in The Ministry of Health Malaysia (NMRR-09893-3579) and Research and Ethical Committee, International Islamic University (ref: IIUM/ 305/ 20/4/10).

Written informed consent was obtained from the participants of this study. A copy of the written consent is available for review by the Editor-in-Chief of this journal.

\section{RESULT}

Table 1 shows the characteristics of the 150 women who participated in the study. There were no significant differences noted with regard to socio-demographics, anthropometrics and duration of infertility between the studied groups, suggesting that they were homogenously distributed. The data were normally distributed.

Table 2 demonstrates the outcomes in terms of ovulation rate, pregnancy rate, single follicle formation and endometrial thickness between the Letrozole and Clomiphene citrate groups among PCOS patients.

Table 3 shows multiple logistic regression analysis for 150 polycystic ovarian syndrome (PCOS) patients receiving Letrozole or Clomiphene citrate. PCOS patients who were randomized to the Letrozole group were approximately 3 times more likely to ovulate compared to the clomiphene citrate group after controlling for other variables such as age, duration of infertility, type of infertility, baseline FSH and LH levels and BMI. [adj. OR $(95 \% \mathrm{CI})=3.02(1.45,6.30) ; \mathrm{p}=0.003]$. Only BMI

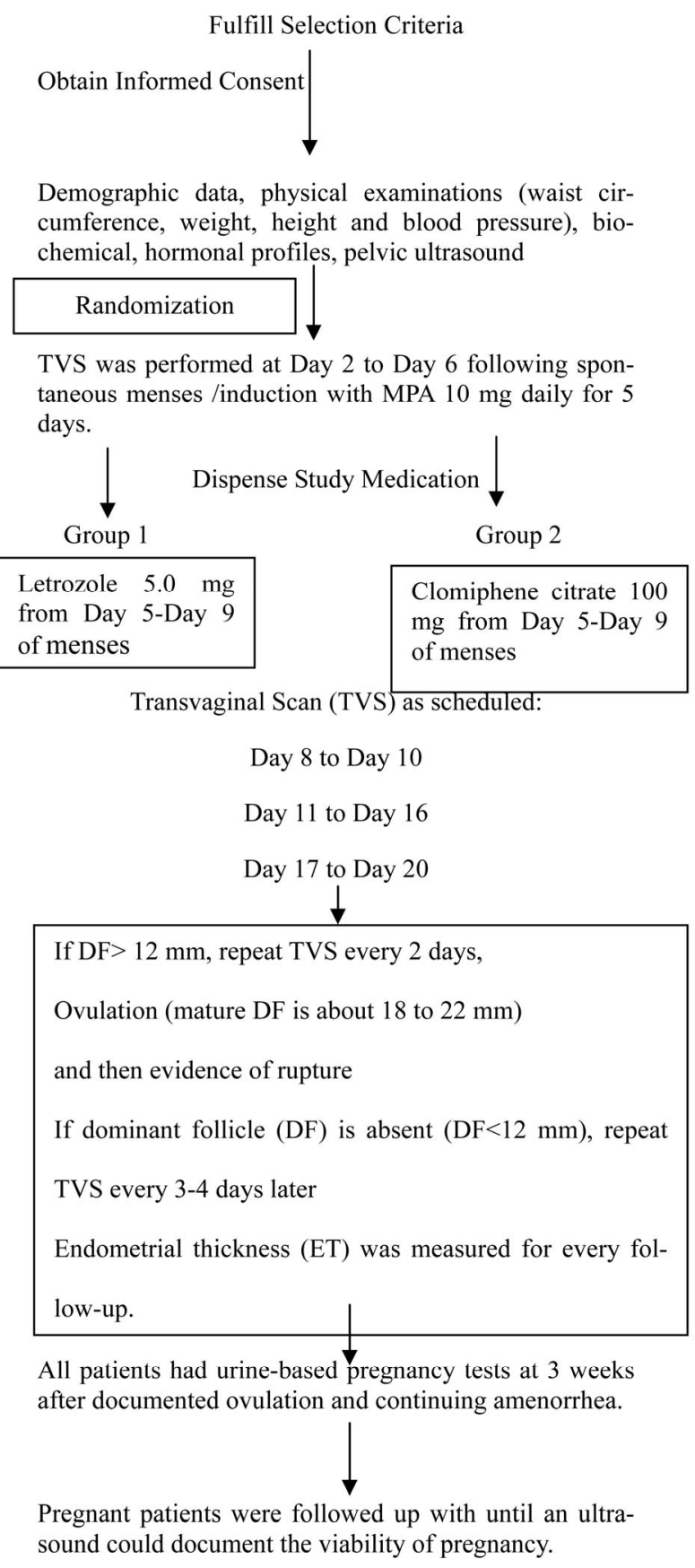

Figure 1. Study flow chart.

made a significant contribution to predicting which patients would have successful ovulation. As the BMI of a patient increases by 1 unit $\mathrm{kg} / \mathrm{m}^{2}$, there is a $9 \%$ reduction in her chances of having a successful ovulation [adj. OR $(95 \% \mathrm{CI})=0.91(0.85,0.97) ; \mathrm{p}=0.004]$.

\section{DISCUSSION}

Clomiphene citrate is an anti-estrogen with a $60 \%-80 \%$ ovulation rate and a $10 \%-20 \%$ pregnancy rate. This is due to the anti-estrogen effect of Clomiphene citrate, 
Table 1. Baseline demographic and clinical characteristics of PCOS patients for each group.

\begin{tabular}{|c|c|c|c|c|}
\hline & \multirow{2}{*}{$\begin{array}{c}\text { All }^{\mathrm{a}} \\
(\mathrm{n}=150)\end{array}$} & \multicolumn{2}{|c|}{ Trial groups $^{\mathrm{a}}$} & \multirow{2}{*}{ p-value } \\
\hline & & Letrozole (n = 75) & Clomiphene citrate $(n=75)$ & \\
\hline Age (years) mean (SD) & $29.4(3.88)$ & $29.3(3.73)$ & $29.4(4.05)$ & 0.983 \\
\hline$<35$ & $135(90.0)$ & $68(90.7)$ & $67(89.3)$ & \multirow{2}{*}{$0.785^{\mathrm{c}}$} \\
\hline$\geq 35$ & $15(10.0)$ & $7(9.3)$ & $8(10.7)$ & \\
\hline \multicolumn{5}{|l|}{ Race (n, \%) } \\
\hline Malay & $138(92.0)$ & $70(93.3)$ & $68(90.7)$ & \multirow{2}{*}{$0.211^{\mathrm{c}}$} \\
\hline Non Malay & $12(8.0)$ & $5(6.7)$ & $7(9.3)$ & \\
\hline \multicolumn{5}{|l|}{ Number of parity } \\
\hline 0 & $120(80.0)$ & $59(78.7)$ & $61(81.3)$ & \multirow[t]{2}{*}{$0.660^{c}$} \\
\hline$\geq 1$ & $30(20.0)$ & $16(21.3)$ & $14(18.7)$ & \\
\hline \multicolumn{5}{|l|}{ Type of infertility } \\
\hline Primary & $116(77.3)$ & $57(76.0)$ & $59(78.7)$ & \multirow[t]{2}{*}{$0.423^{\mathrm{c}}$} \\
\hline Secondary & $34(22.7)$ & $18(24.0)$ & $16(21.3)$ & \\
\hline \multicolumn{5}{|l|}{ Duration of infertility } \\
\hline mean & $4.5(2.5)$ & $4.5(2.5)$ & $4.5(2.6)$ & 0.948 \\
\hline$<5$ & $89(59.3)$ & $45(60.0)$ & $44(58.7)$ & \multirow[b]{2}{*}{$0.868^{\mathrm{c}}$} \\
\hline$\geq 5$ & $61(40.7)$ & $30(40.0)$ & $31(41.3)$ & \\
\hline \multicolumn{5}{|l|}{ Menstrual cycle } \\
\hline Age of menarche & & $12.33(1.41)$ & $12.55(1.31)$ & 0.338 \\
\hline regular & $25(16.7)$ & $12(16.0)$ & $13(17.3)$ & \multirow{2}{*}{$0.827^{\mathrm{c}}$} \\
\hline irregular & $125(83.3)$ & $63(84.0)$ & $62(82.7)$ & \\
\hline
\end{tabular}

${ }^{a}$ Values are expressed as the mean (standard deviation, SD), unless otherwise specified. ${ }^{b}$ Independent $t$ test. ${ }^{c}$ Pearson chi-squared test.

Table 2. Comparison of outcomes (ovulation rate, pregnancy rate, single follicle formation and endometrial thickness) between Letrozole and Clomiphene citrate groups.

\begin{tabular}{cccccc}
\hline Outcome parameters & Letrozole $(\mathbf{n}=\mathbf{7 5})$ & Clomiphene citrate $(\mathbf{n}=\mathbf{7 5})$ & Relative ratio $^{\ddagger}(\mathbf{9 5 \%} \mathbf{C I})$ & $\mathbf{p ~ v a l u e}$ \\
\hline Ovulation rate, $\mathbf{n}(\%)$ & $59(78.7)$ & $40(53.3)$ & $1.48(1.16,1.88)$ & $\mathbf{0 . 0 0 1 ^ { \mathrm { c } }}$ \\
Pregnancy rate, $\mathbf{n}(\%)$ & $19(25.3)$ & $12(16.0)$ & $1.58(0.83,3.03)$ & $0.221^{\mathrm{c}}$ \\
Single follicle, $\mathbf{n}$ (\%) & $33(44.6)$ & $20(26.7)$ & $1.22(0.75,1.99)$ & $0.270^{\mathrm{c}}$ \\
$\begin{array}{c}\text { Endometrial thickness at } \\
\text { D11-14 (mm) Mean (SD) }\end{array}$ & $9.2(2.3)$ & $8.4(2.2)$ & $1.6(0.1,3.2)^{\dagger}$ & $\mathbf{0 . 0 3 1}^{\mathrm{b}}$ \\
\hline
\end{tabular}

${ }^{\dagger}$ mean difference (mm) with its $95 \%$ CI. ${ }^{c}$ Pearson chi-square; ${ }^{\text {bindependent } t} \mathrm{t}$ test; $\mathrm{p}<0.05$ is significant.

Table 3. Multiple logistic regression analysis for 150 polycystic ovarian syndrome (PCOS) patients receiving Letrozole or Clomiphene citrate.

\begin{tabular}{ccccc}
\hline Variables & Adj. $\mathbf{O R}(\mathbf{9 5} \% \mathbf{C I})^{*}$ & Wald's test & df & p value \\
\hline Trial groups & 1.00 & 8.667 & 1 & $\mathbf{0 . 0 0 3}$ \\
Clomiphene citrate & & & & \\
Letrozole & $3.02(1.45,6.30)$ & 8.301 & 1 & $\mathbf{0 . 0 0 4}$ \\
Body Mass Index $\left(\left(\mathrm{kg} / \mathrm{m}^{2}\right)\right.$ & $0.91(0.85,0.97)$ & & \\
\hline
\end{tabular}


resulting in long-lasting estrogen receptor (ER) depletion. Clomiphene citrate accumulates in the body due to its long half-life ( 2 weeks), causing adverse effects on the quality and quantity of cervical mucus. In addition, it affects endometrial development, causing implantation failure and significant thinning of the endometrium. These undesirable effects of Clomiphene citrate on the endometrium may explain the relatively poor pregnancy rate associated with Clomiphene citrate despite the high rate of ovulation [7].

Letrozole is a type IIa third-generation highly selective cytochrome P-450-linked aromatase inhibitor that prevents androgen-to-estrogen conversion. Letrozole has the same mechanism as Clomiphene citrate in initiating gonadotropin release through the withdrawal of negative feedback on the pituitary by reducing blood estrogen levels. Clomiphene citrate blocks estrogen receptors (ERs) to mimic estrogen deficiency in the pituitary, while Letrozole creates an estrogen deficiency by blocking the conversion of androgen to estrogen. Hence, the initial release of FSH may be increased in patients treated with Letrozole than in those treated with Clomiphene citrate.

In the ovary, aromatase inhibitors increase follicular sensitivity to FSH by the accumulation of intraovarian androgens. As the dominant follicle grows and estrogen levels rise, normal negative feedback occurs centrally, resulting in suppression of FSH secretion and atresia of the smaller growing follicles. A single dominant follicle and monoovulation should occur in most cases [8]. In the endometrium, estrogen receptors may be upregulated, resulting in rapid endometrial growth once estrogen secretion is restored following clearance of Letrozole [9].

\subsection{Number of Ovulations}

Ovulation was significantly more frequent in the Letrozole group $59(78.7 \%)$ than Clomiphene citrate group $40(53.3 \%)$, which was statistically significant with $\mathrm{p}$ value of 0.001 (Table 2). Other studies showed similar ovulation rates of $82.4 \%$ and $63.2 \%$ for Letrozole and Clomiphene citrate, respectively. Previously published studies reported ovulation rates for Letrozole and Clomiphene citrate of $82.4 \%$ and $63.2 \%$, respectively [10]. Another study found that among women taking Letrozole, $62.5 \%$ had achieved ovulatory cycling as compared to $37.5 \%$ of women taking Clomiphene citrate, which was not different significantly [7]. How- ever, our study correlates with previously reported data that Letrozole increases the percentage of women achieving ovulatory stimulation. Another study comparing Letrozole and combined metformin-Clomi- phene citrate treatment showed no difference in rates of ovulation and pregnancy [10].

Ultrasound variability is an important confounding factor, particularly if follicle size is the main deciding factor of ovulation induction. This becomes especially true when ultrasonography reveals a collapsed follicle that has already ovulated. Measuring such a follicle can result in a misclassification bias where the diameter of the follicle is assigned to an incorrect category and, hence, underestimates the true value.

\subsection{Endometrial Response}

Endometrial thickness (ET) measurement is a predictor for successful implantation following ovulation induction, with many studies reporting more success with a thickness of $9-10 \mathrm{~mm}$. In our study, mean ET in the Letrozole group was thicker than in the Clomiphene citrate group at midcycle of menses (Day 11-Day 14), with ET values of $9.2 \mathrm{~mm}(\mathrm{SD} \pm 2.3)$ and $8.4 \mathrm{~mm}(\mathrm{SD} \pm 2.2)$, respectively (Table 2). This difference was statistically significant as denoted by a $\mathrm{p}$ value of 0.031 . These findings were consistent with other studies reporting that most patients taking Letrozole had a thicker endometrium $(8.4 \mathrm{~mm})$ and conceived more frequently (21.6\% pregnancy rate) compared to those taking Clomiphene citrate $(5.2 \mathrm{~mm}$ endometrial thickness and $9.1 \%$ pregnancy rate) [11]. Similar findings showed that Letrozole had an overall greater beneficial effect on the endometrium $[8,12]$.

Surprisingly, another study [4] revealed that the endometrium was statistically significantly thicker in the Clomiphene citrate group, possibly due to an increase in the number of growing follicles and thus a higher level of estrogen and progesterone, although endometrial thickness in both study groups was $>5$ or $6 \mathrm{~mm}$.

\subsection{Number of Pregnancies}

Historically, the overall successful pregnancy rates after ovulation induction range from as low as $9 \%$ to as high as $25 \%$ [13]. These controversies may stem from differences in the treatment groups, diagnostic criteria, techniques used, age of the cohort, cause of infertility and the number of treatment cycles. In our study, consistent with the number of successful ovulatory cycles, pregnancy rate was notably higher in the Letrozole treatment group compared to the Clomiphene citrate group with 19 $(25.3 \%)$ and $12(16.0 \%)$ pregnancies, respectively; however, this was not significantly different. The pregnancy rate observed in our study was consistent with other reported studies such as that by Mitwally [14], in which a pregnancy rate of $25 \%$ was observed for PCOS patients treated with $2.5 \mathrm{mg}$ Letrozole. Additionally, Atay [11] also found a pregnancy rate of $21.6 \%$ after treatment with $2.5 \mathrm{mg}$ Letrozole and $9.1 \%$ after treatment with 100 mg Clomiphene citrate, which was statistically significantly different. There are a few studies that showed significantly higher pregnancy rates with Letrozole than with Clomiphene citrate $[15,16]$. 
Generally, conception should result within six treatment cycles. Beyond that, pregnancy rate is lower because the cohort of women remaining represents the harder to obtain pregnant cases. Hence, only newly diagnosed and nontreated women were included in the present study to minimize bias.

Pregnancy rate may be altered by other confounding factors; for example, approximately $10 \%$ of women in our study were more than 35 years old. This factor lowered the number of pregnancies and made the study sample a relatively less fertile group.

Current studies have shown that Letrozole is generally safe for use in pregnancy [17]. Known complications of Clomiphene citrate use include multifetal pregnancy and pregnancy wastage. A major complication associated with the use of Clomiphene citrate is the occurrence of ovarian hyperstimulation syndrome (OHSS). All complications of this therapy are essentially related to the degree of ovarian stimulation that occurs during ovarian induction. In this study, no subjects had multiple pregnancies or OHSS.

\section{CONCLUSION}

In this study, Letrozole was noted to be better at ovulation induction as the ovulation rate was $78.7 \%$ and $53.3 \%$, respectively which is statistically significantly with $\mathrm{p}$ value of 0.001 . The mean ET in the Letrozole group was statistically significantly thicker than in the Clomiphene citrate group at midcycle of menses (Day 11-Day 14), with values of $9.2 \mathrm{~mm}(\mathrm{SD} \pm 2.3)$ and 8.4 $\mathrm{mm}(\mathrm{SD} \pm 2.2)$, respectively $(\mathrm{p}=0.031)$. The Letrozole group had a higher pregnancy rate compared to the Clomiphene citrate group with $25.3 \%$ and $16.0 \%$ of subjects achieving pregnancy, respectively, but this was not statistically significant $(\mathrm{p}=0.158)$. Apart from that, Letrozole treatment is prone to production of monofollicles and hence leads to reduced incidences of the adverse pregnancy outcome of multiple fetuses as compared to treatment with Clomiphene citrate. Overall, this study demonstrates that Letrozole is superior to Clomiphene citrate as an inducer of ovulation cycles.

\section{ACKNOWLEDGEMENTS}

This study was funded by a Research University Grant from Universiti Sains Malaysia (USM) (1001/PPSP/812040). We would like to express our highest gratitude to the efforts of Universiti Sains Malaysia (USM) for funding this research.

\section{REFERENCES}

[1] Rotterdam ESHRE/ASRM-Sponsored PCOS Consensus Workshop Group (2004) Revised 2003 consensus on diagnostic criteria and long-term health risks related to polycystic ovary syndrome. Fertility and Sterility, 81, 19-
25.

[2] Diamanti-Kandarakis, E., Kouli, C.R., Bergiele, A.T., Filandra, F.A., Tsianateli, T.C., Spina, G.G., Zapanti, E.D. and Bartzis, M.I. (1999) A survey of the polycystic ovary syndrome in the Greek island of Lesbos: hormonal and metabolic profile. The Journal of Clinical Endocrinology \& Metabolism, 84, 4006-4011. doi: $10.1210 /$ jc. 84.11 .4006

[3] Knochenhauer, E.S., Key, T.J., Kahsar-Miller, M., Waggoner, W., Boots, L.R. and Azziz, R. (1998) Prevalence of the polycystic ovary syndrome in unselected black and white women of the southeastern United States: A prospective study. The Journal of Clinical Endocrinology \& Metabolism, 83, 3078-3082. doi: $10.1210 /$ jc. 83.9 .3078

[4] Badawy, A., Abdel-Aal, I. and Abulatta, M. (2009) Clomiphene citrate or letrozole for ovulation induction in women with polycystic ovarian syndrome: A prospective randomized trial. Fertility and Sterility, 92, 849-852. doi:10.1016/j.fertnstert.2007.02.062

[5] Sohrabvand, F., Ansari, S. and Bagheri, M. (2006) Efficacy of combined metformin-letrozole in comparison with metformin-clomiphene citrate in clomiphene-resistant infertile women with polycystic ovarian disease. Human Reproduction, 21, 1432-1435. doi:10.1093/humrep/del020

[6] Holzer, H., Casper, R. and Tulandi, T. (2006) A new era in ovulation induction. Fertility and Sterility, 85, 277-284. doi:10.1016/i.fertnstert.2005.05.078

[7] Begum, M.R., Ferdous, J., Begum, A. and Quadir, E. (2009) Comparison of efficacy of aromatase inhibitor and clomiphene citrate in induction of ovulation in polycystic ovarian syndrome. Fertility and Sterility, 92, 853-857. doi:10.1016/j.fertnstert.2007.08.044

[8] Mitwally, M.F. and Casper, R.F. (2006) Potential of aromatase inhibitors for ovulation and superovulation induction in infertile women. Drugs, 66, 2149-2160. doi:10.2165/00003495-200666170-00001

[9] Casper, R.F. and Mitwally, M.F. (2006) Review: Aromatase inhibitors for ovulation induction. The Journal of Clinical Endocrinology \& Metabolism, 91, 760-771. doi:10.1210/jc.2005-1923

[10] Abu Hashim, H., Shokeir, T. and Badawy, A. (2010) Letrozole versus combined metformin and clomiphene citrate for ovulation induction in clomiphene-resistant women with polycystic ovary syndrome: A randomized controlled trial. Fertility and Sterility, 94, 1405-1409. doi:10.1016/j.fertnstert.2009.07.985

[11] Atay, V., Cam, C., Muhcu, M., Cam, M. and Karateke, A. (2006) Comparison of letrozole and clomiphene citrate in women with polycystic ovaries undergoing ovarian stimulation. Journal of International Medical Research, 34, 73-76. doi:10.1177/147323000603400109

[12] Banerjee Ray, P., Ray, A. and Chakraborti, P.S. (2012) Comparison of efficacy of letrozole and clomiphene citrate in ovulation induction in Indian women with polycystic ovarian syndrome. Archives of Gynecology and Obstetrics, 285, 873-877.

doi:10.1007/s00404-011-2091-7 
[13] Balen, A. (2000) Ovulation induction for polycystic ovary syndrome. Fertility and Sterility, 3, 106-111. doi:10.1080/1464727002000198791

[14] Mitwally, M.F. and Casper, R.F. (2001) Use of an aromatase inhibitor for induction of ovulation in patients with an inadequate response to clomiphene citrate. Fertility and Sterility, 75, 305-309. doi:10.1016/S0015-0282(00)01705-2

[15] Badawy, A., Mosbah, A., Tharwat, A. and Eid, M. (2009) Extended letrozole therapy for ovulation induction in clomiphene-resistant women with polycystic ovary syn- drome: A novel protocol. Fertility and Sterility, 92, 236239. doi:10.1016/j.fertnstert.2008.04.065

[16] Kar, S. (2012) Clomiphene citrate or letrozole as first-line ovulation induction drug in infertile PCOS women: A prospective randomized trial. Journal of Human Reproductive Sciences, 5, 262-265. doi:10.4103/0974-1208.106338

[17] Elizur, S.E. and Tulandi, T. (2008) Drugs in infertility and fetal safety. Fertility and Sterility, 89, 1595-1602. doi:10.1016/j.fertnstert.2008.02.092 